\title{
SURFACE MODIFICATION OF CARBON FIBRES USING PLASMA TECHNIQUE
}

\author{
Iris Käppler*, Rolf-Dieter Hund, Chokri Cherif \\ Institute of Textile Machinery and High Performance Material Technology, Technische Universität Dresden, Hohe Straße 6, 01062 Dresden, Germany \\ E-mail: Iris.Kaeppler@tu-dresden.de
}

\begin{abstract}
:
For the development of a new generation non-crimp fabrics (NCF) made of carbon fibres, a feasibility study of different characterisation methods and surface treatments of the used carbon fibres needs to be performed. In order to join the carbon fibre layers with the binder for realising this new type of NCF, the surface topography and functionality of the fibres have to be analysed first. The wettability of the binder to the carbon fibre surface is of prime significance and needs to be enhanced. Here, the enhancement is carried out by improving the surface energy using atmospheric plasma of compressed air, argon and nitrogen. It is also proposed to improve the surface energy through chemical techniques.
\end{abstract}

\section{Keywords:}

Acid treatment, Atmospheric plasma, Carbon fibres, Surface functionalisation

\section{Introduction}

In the present scenario, adhesive bonding is seen as an equivalent alternative to the existing classical bonding method in mechanical engineering applications. The use of adhesive enables non-destructive joining in the field of technical textiles [1] as an alternative to the classical stich bonding [8]. For yarn joining, a careful and suitable technique can be guaranteed by the use of binders, which is the main target of the junior researcher project SAXOMAX. Accordingly, a new production technology for multiaxial fabrics will be developed and feasibility studies carried out to examine different binders, surface modification techniques and carbon fibres itself. Therefore, the focus of this work is the investigation of the carbon fibre surface, especially surface structure and morphology as well as surface tension. Surface tension is used to estimate the wettability of the carbon fibre using selected adhesive samples. The investigated fibres have different sizings and tensile strength.

\section{Materials and Methods}

\section{Carbon Fibres}

Carbon fibres are of interest due to their high mechanical load bearing properties, anisotropic graphite lattice and stiffness [3]. Polyacrylonitrile based carbon fibres were used for the studies. High-tensile (HT) modulus yarns and ultra-modulus strength (UMS) fibre were purchased from Toho Tenax Europe $\mathrm{GmbH}$ (Wuppertal, Germany) with two different sizings such as polyurethane (PU) and epoxy (EP). All mechanical properties, as denoted by the manufacturer, are presented in Table 1. The diameter of all carbon fibre samples was determined with a light microscope.

By the use as composite reinforcement, investigations with $X$-ray diffraction, high-resolution electron microscopy, scanning electron microscopy (SEM) and contact angle measurements were done to evaluate the wetting and adhesion properties

Table 1. Mechanical properties of used carbon fibre [5]

\begin{tabular}{|l|c|c|c|c|}
\hline \multicolumn{2}{|c|}{ Property } & $\begin{array}{c}\text { Tenax®-E } \\
\text { HTS 45 E23 }\end{array}$ & $\begin{array}{c}\text { Tenax®-E } \\
\text { HTS 40 F13 }\end{array}$ & $\begin{array}{c}\text { Tenax } ® \text {-J } \\
\text { UMS 40 F23 }\end{array}$ \\
\hline \multicolumn{2}{|c|}{ Sizing } & PU-sizing & EP-sizing & PU-sizing \\
\hline Linear density & {$[\mathrm{tex}]$} & 796.4 & 797.6 & 24 \\
\hline Grade & {$[\mathrm{K}]$} & 12 & 12 & 389.0 \\
\hline Young's modulus & {$[\mathrm{GPa}]$} & 240.2 & 239.0 & 4626.0 \\
\hline Tensile strength & {$[\mathrm{MPa}]$} & 4519.7 & 4551.3 & 1.19 \\
\hline Breaking elongation & {$[\%]$} & 1.76 & 1.78 & 1.77 \\
\hline Density & {$\left[\mathrm{g} / \mathrm{m}^{3}\right]$} & 1.77 & 6.30 & 4.40 \\
\hline Diameter of a single filament (average) & {$[\mu \mathrm{m}]$} & 6.19 & \\
\hline
\end{tabular}


as well as the surface morphology. The primary interest was to increase the number of surface active groups to improve the bonding of fibres to the matrix or adhesive. A conventional method is the use of vacuum plasma techniques to introduce oxygen-containing functional groups by oxygen or aliphatic amines by ammonia and nitrogen plasma [9].

\section{Analysis of the Surface Structure}

SEM was used to examine the fibre surface in the micrometre range. The measurements were performed using a highresolution lowvoltage SEM with a field emission cathode Zeiss DSM 982 Gemini. All SEM investigated carbon fibre samples were treated with the same velocity of the plasma torch that presupposes the same processing time.

\section{Determination of Surface Tension}

In order to estimate the wetting properties, the contact angle $\Theta$ was measured and the surface tension $Y$ was calculated by the method of Owens, Wendt, Rabel and Kaelble [4] as:

$$
\frac{\gamma_{l}(1+\cos \theta)}{2 \sqrt{\gamma_{l}^{d}}}=\sqrt{\gamma_{s}^{p}}\left(\frac{\gamma_{l}^{p}}{\gamma_{l}^{d}}\right)+\sqrt{\gamma_{s}^{d}}
$$

This model is used for single filaments and for a sessile drop. In both cases, the contact angle is a parameter of the degree of attraction of the liquid by the substrate and gives the levels of hydrophobicity. The surface tension is divided into the polar component $\left({ }^{p}\right)$ and the disperse component $\left({ }^{d}\right)$. The polar component $\left({ }^{p}\right)$ is affected by dipol-dipol interactions, hydrogen bonds and acid-base interaction. The disperse component (d) or dispersion forces are mainly driven by van der Waals' forces [4]. Here, the surface tension was determined using a Krüss K 100 (Krüss $\mathrm{GmbH}$, Germany).

\section{Improving the Surface Energy}

A plasma torch (Plasma brush $® \mathrm{~Pb} 2$, Rheinhausen Plasma $\mathrm{GmbH}$, Germany) was used to modify the surface of carbon fibres with atmospheric plasma. The use of a plasma torch retains the mechanical properties of carbon fibres such as the HT strength and Young's modulus. Different technical gases were employed, such as compressed air, argon and nitrogen. The argon was of industrial grade with 99.999 Vol.\% purity, which was purchased from Air Liquide (Düsseldorf, Germany). The used fibres were not cleaned from their sizing.

\section{$\underline{\text { X-Ray Photoelectron Spectroscopy }}$}

It is a proven and significant technique for understanding the surface and predicting the interface behaviour [7]. The information of the surface elemental composition was acquired using a Physical Electronics PHI 5700 ESCA System with an Al Ka anode. The sample depth reached was less than $9 \mathrm{~nm}$. Single peaks were measured with the pass energy of $29.35 \mathrm{eV}$ for high resolution spectra. The binding energies of the X-ray photoelectron spectroscopy (XPS) spectra were analysed at $284 \sim 291 \mathrm{eV}$ for carbon (C1s). The X-ray irradiation was set under 250 watts. Quantitative analysis was performed with the standard $\mathrm{PHI}$ software.

The vacuum chamber was set on at $5 \cdot 10^{-10}$ torr. All XPS investigated carbon fibre samples are treated with the same velocity of plasma torch and exhibit the same processing time.

\section{Results and Discussion}

\section{Microscopic Studies}

In order to achieve a good adhesion between the adhesive and the adherend, the surface of the adherend, i.e. its wettability and morphology, has to be known. All investigated carbon fibres show striations and parallel oriented stripes in the SEM images, as shown in Figure 1. Often, they are frequently filled with the PU or EP sizing. Some of the carbon fibres show imperfections and particles (Figure 1) that can be induced by the sizing or by the intrinsic structure as shown in Figure 2. This parallel ordered structure is caused by a stretching of the fibrous polyacrylonitrile precursor [6] and is shown in Figure 3.

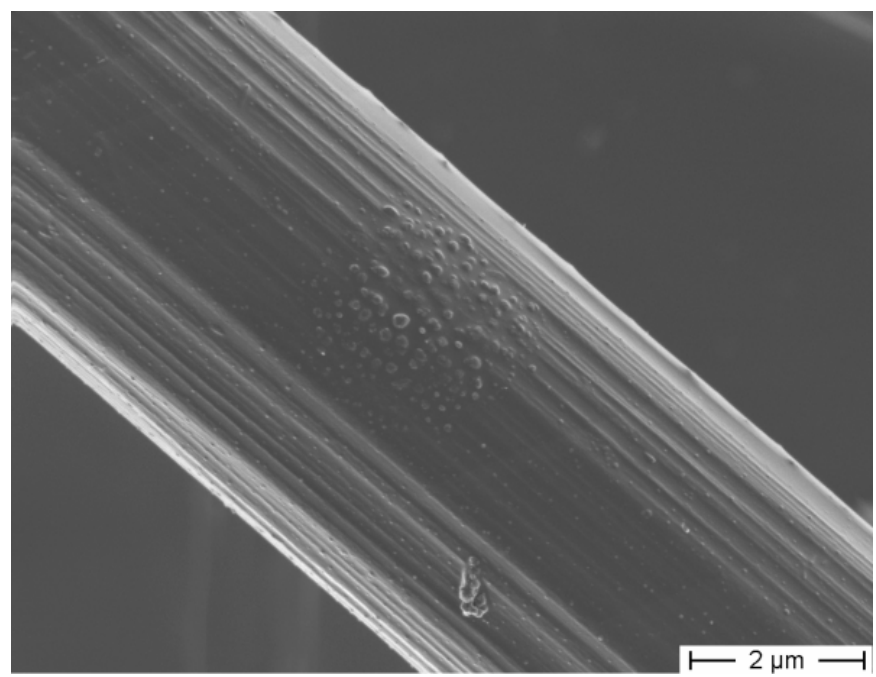

Figure 1. UMS 40 F23 carbon fibre with polyurethane sizing, SEM

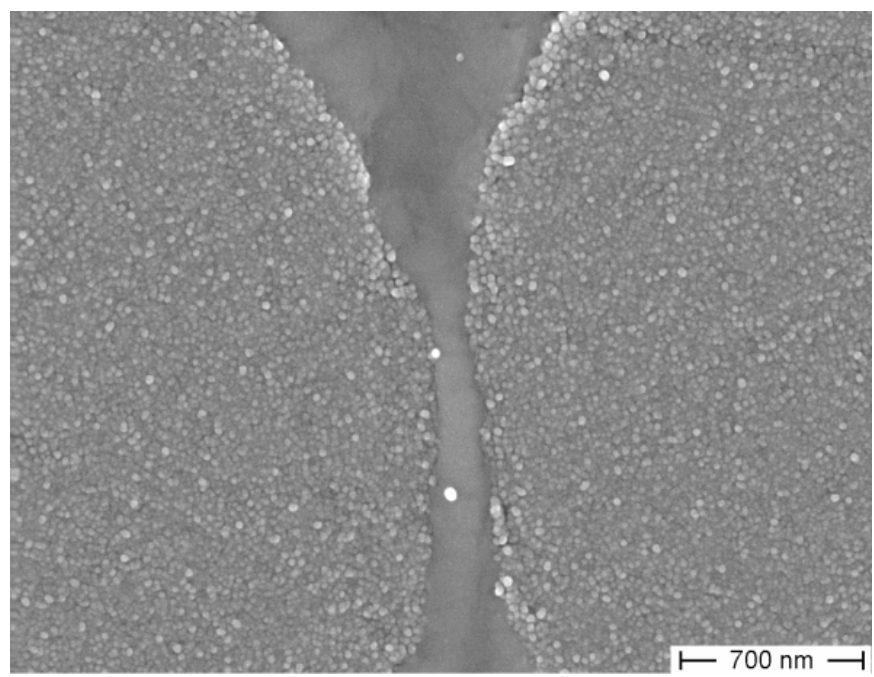

Figure 2. Cross-section, UMS 40 F23 carbon fibre with polyurethane sizing, SEM 

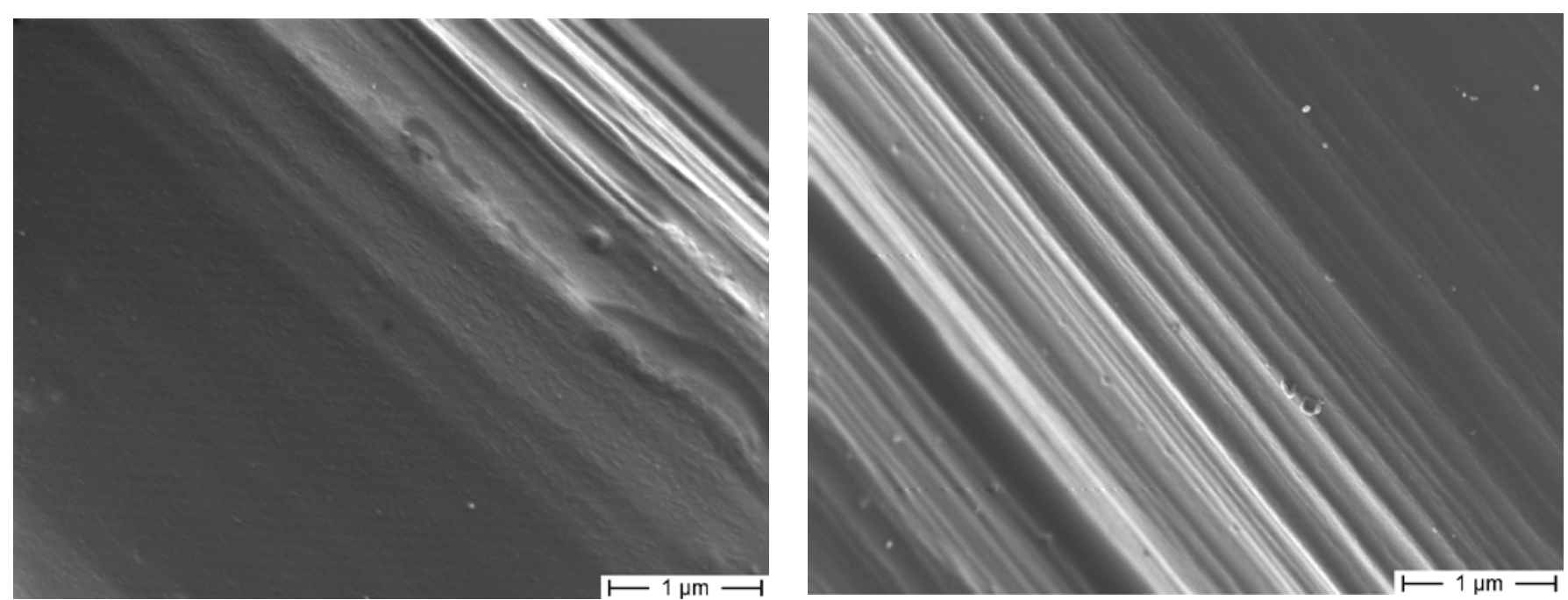

C

$\mathrm{D}$
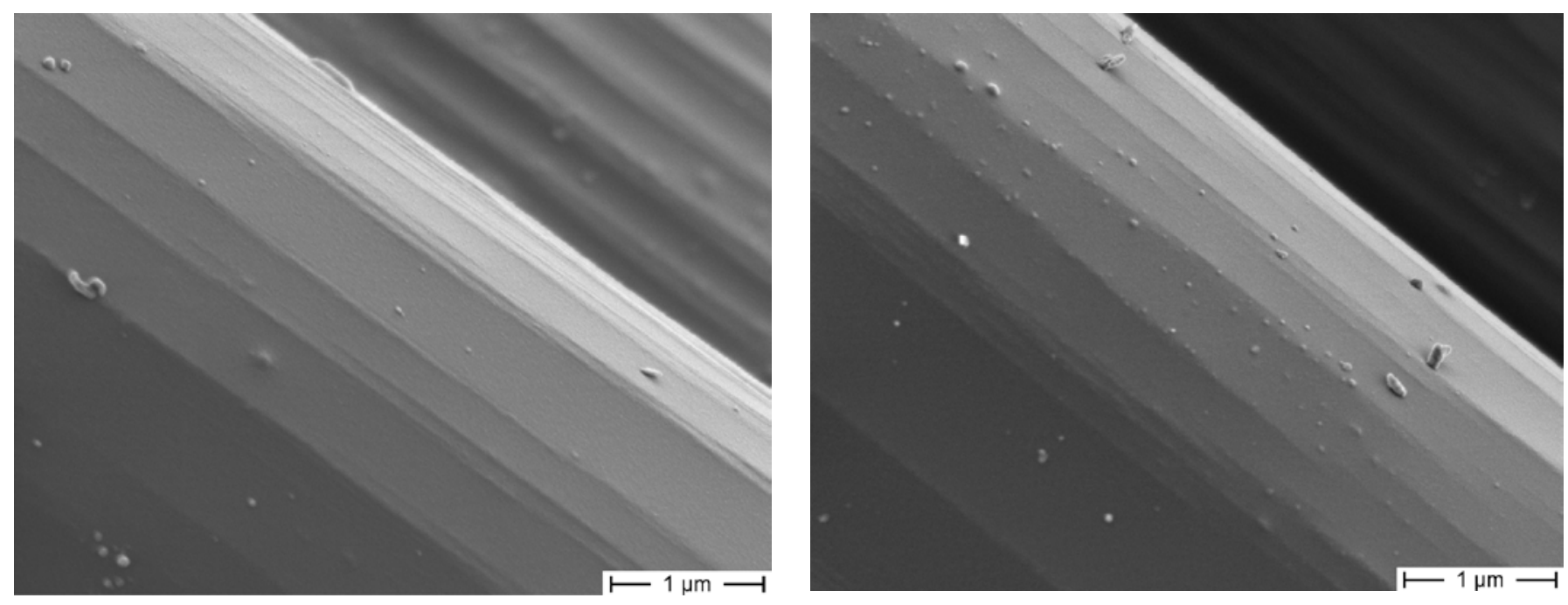

$E$

F
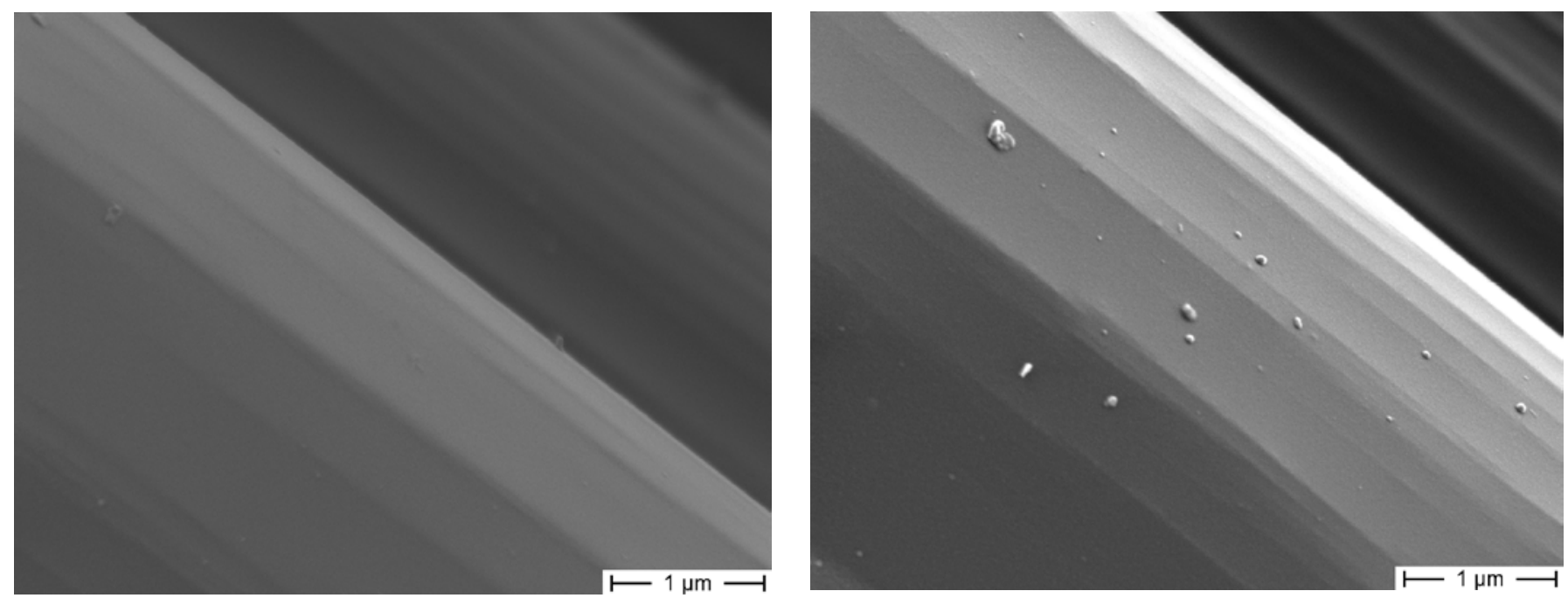

Figure 3. SEM images of plasma-treated carbon fibres compared with non-treated samples; A: HTS 45 E23 without treatment; B: HTS 40 F13 without treatment; C: HTS 45 E23 after air atmospheric plasma treatment; D: HTS 40 F13 after air atmospheric plasma treatment; E: HTS 45 E23 after argon atmospheric plasma treatment; F: HTS 40 F13 after argon atmospheric plasma treatment 
After the plasma treatment, the surface is significantly smoother compared with the original state as can be seen in Figure 3. The striations and particles on the surface are less obvious and flat. This is shown for the use of compressed air plasma as well as argon plasma. Particles in nanometre scale are found in the samples consisting of PU sized carbon fibres. They are recognisable for both untreated (Figure $3 A$ and $B$ ) and treated samples (Figure $3 \mathrm{D}$ and $\mathrm{F}$ ). They are exposed to the surface after removing the sizing using plasma. The surface is more pristine after the use of argon plasma (Figure $3 \mathrm{E}$ and $\mathrm{F}$ ) compared with the air plasma (Figure $3 \mathrm{C}$ and $\mathrm{D}$ ) due to its higher energy.

With regard to the final use and application of a binder system on the carbon fibre surface, the surface becomes clean after the use of a plasma torch and the micro-roughness increases [2]. The sizing is removed by this high energy technique.

\section{Wetting Studies}

It can be inferred from Table 2 that the surface tension of all investigated carbon fibres is comparable with each other. Here, only the polar components induced by the functional groups on the surface differ, which in turn depends on their varied sizing. After the treatment with the plasma torch, the polar component decreases.

A smaller velocity corresponds to a higher dwell period. Therefore, there is more time to generate new functional, polar groups. This is shown in Table 3. Furthermore, the polar component of the untreated samples is greater than the treated ones. This can be induced by removing the sizing using plasma and a lower amount of new generated functional groups afterwards.

\section{XPS Studies}

The atmospheric plasma-treated samples were evaluated with XPS measurements. The chemical composition of the surface was studied with the absorption effects of X-rays. The peaks describe different kinds of chemical bonds, for example of carboxyl groups (peak at 289.3 eV), bonded oxygen (287.4 eV), nitrile groups/surface-free hydroxyl groups (286.7 eV) and graphitic carbon $(284.6 \mathrm{eV})$ [10]. The quantity of the chemical bonds is given in at\% (atomic per cent). All investigated energy bands can be found under the C1 signal of the investigated specimens. The XPS technology is an additional technique for determining the polar and dispersing surface-free energies of the fibre. It determines the polar contributions by the exhibited acidic or amphoteric properties [7].

The initial situation of the surface is characterised by the composition of the particular sizing. The major component of the fibres is carbon followed by oxygen. The fibres also exhibit nitrogen that is a result of the used sizings especially PU. The carbon fibres coated with EP sizing HTS 45 E23 are defined by a high amount of surface-free hydroxyl groups (10.5 at\%), carbon-carbon double bonds with 46 at\% and bound oxygen as ether group with $\sim 18$ at\%. Compared with this, the carbon fibre with PU sizing (HTS 40 F13) exhibits a comparably low amount of carbon-carbon double groups (12.5 at\%) and ether groups (6.1 at\%), but a high content of sp3 with 18.7 at $\%$ and radical sp3 bonds of 35.8 at $\%$.

According to Figure 3 , the plasma treatment removes the upper layer of the surface. Therefore, the composition of the surface changes as well. The sizing is removed and also new functional groups can be induced. The treatment with compressed air plasma increases the ether groups to 8.2 at $\%$ and induces bonded oxygen with an amount of 3.3 at $\%$ for the carbon fibre with PU sizing (HTS 40 F13). In the case of treated carbon fibre with EP sizing (HTS 45 E23), the peak of ether groups and double bounded nitrogen remains nearly constant. But the amount of double bounded carbon decreases from 46.2 at $\%$ to 30.2 at $\%$. Here, it can be expected that the sizing is removed using plasma and more conventional carbon with $\mathrm{sp}^{3}$ hybridisation is recognisable. The use of argon atmospheric plasma decreases the amount of free surface hydroxyl groups of PU coated carbon fibre from 35.8 at $\%$ to 23 at $\%$. But the quantity of oxygen rich groups increases: bounded oxygen with 5.5 at $\%$ and carboxyl groups of 2.2 at\%. The surface becomes more polar as well as more active - the hydroxyl groups and the carboxyl groups are responsible for the acidity of carbon fibres [7]. The atomic concentration of oxygen rises

Table 2. Surface tension of different carbon fibres with different sizing from Toho Tenax Europe GmbH (Wuppertal, Germany)

\begin{tabular}{|c|c|c|c|c|}
\hline \multicolumn{2}{|c|}{ Carbon Fibre } & HTS 45 E23, 12K & HTS 40 F13, 12K & UMS 40 F23, 24K \\
\hline$Y_{s}^{\text {total }}$ & {$[\mathrm{mN} / \mathrm{m}]$} & 60.8 & 71.9 & 69.0 \\
\hline$Y_{s}^{p}$ & {$[\mathrm{mN} / \mathrm{m}]$} & 10.0 & 21.1 & 18.2 \\
\hline$Y_{s}^{d}$ & {$[\mathrm{mN} / \mathrm{m}]$} & 50.8 & 50.8 & 50.8 \\
\hline
\end{tabular}

Table 3. HTS 45 E23, technical air plasma treated with technical air with two different velocities

\begin{tabular}{|c|c|c|c|c|}
\hline \multicolumn{2}{|c|}{ Velocity of Plasma Torch } & $50 \mathrm{~mm} / \mathrm{s}$ & $150 \mathrm{~mm} / \mathrm{s}$ & $400 \mathrm{~mm} / \mathrm{s}$ \\
\hline$Y_{s}^{\text {total }}$ & {$[\mathrm{mN} / \mathrm{m}]$} & 57.5 & 56.8 & 57.5 \\
\hline$Y_{s}^{p}$ & {$[\mathrm{mN} / \mathrm{m}]$} & 6.0 & 6.8 & 12.0 \\
\hline$Y_{s}^{d}$ & {$[\mathrm{mN} / \mathrm{m}]$} & 50.7 & 50.8 & 47.6 \\
\hline
\end{tabular}




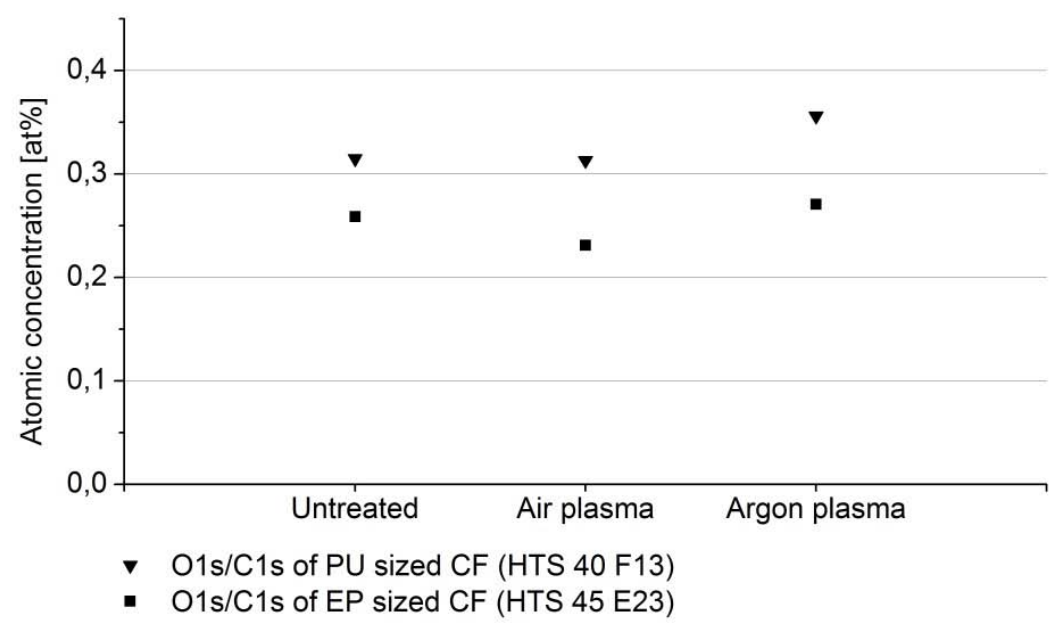

Figure 4. Atomic concentration of oxygen (oxygen peak, O1s) to carbon (carbon peak, C1s) from untreated, air treated and argon plasma-treated carbon fibre

as a consequence of the use of argon plasma for both types of fibres. In Figure 4, it can be seen that the content of oxygen at the surfaces is higher after the argon plasma treatment compared with the untreated sample.

The EP coated carbon fibres show a small increase of oxygencontaining groups and only for ether groups. It is obvious that there is no establishment of oxygen-containing groups such as bonded oxygen and carboxyl groups at the carbon fibre with EP sizing by plasma.

\section{Conclusions}

The plasma treatment is a promising technique to improve the surface properties of carbon. It is recognisable that the amount of oxygen at the surface of carbon fibre increases by the use of argon atmospheric plasma technique. The use of compressed air plasma exhibits only a small increase of functionalisation. A smoothing of the carbon fibre surface through plasma technique is observable by SEM.

In order to increase the wettability of carbon fibres, further investigations need to be done using wet chemical methods such as the nitric acid. Another promising method is the oxy fluorination of the carbon fibres to functionalise and homogenise the surface.

\section{Acknowledgements}

Financial support of this work by the European Social Fund (ESF 100106845, "SAXOMAX") and the Free State of Saxony is gratefully acknowledged.
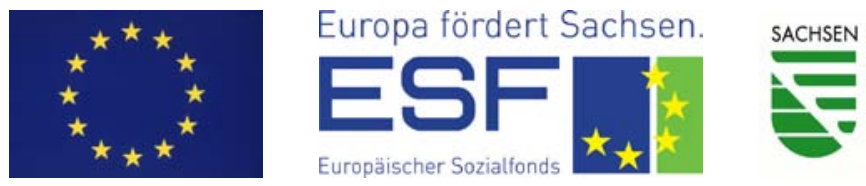

\section{References}

[1] Beiß, T.: Vibrationsfügen von duroplastischen Faserverbunden mit abrasive Schmelzklebstoffen auf Basis von Polyamid, Universität Erlangen-Nürnberg, PhD Thesis, (2009)

[2] Blasek, G.; Bräuer, G.: Vakuum, Plasma, Technologien Beschichtung und Modifizierung von Oberflächen, Teil I, Eugen G. Leutze Verlag KG, ISBN 978-3-87480-257-4, Bad Saulgau, first edition. (2010)

[3] Guigon, M.; Oberlin, A.; Desarmont, G.: Microtexture and structure of some high tensile strength, PAN-Base carbon fibres, Fibre Science and Technology, 20(1984), pp. 55-72

[4] Hoecker, F.; Karger-Kocsis, J.: Surface energetics of carbon fibers and its effects on the mechanical performance of CF/EP composites, Journal of Applied Polymer Science, 59(1996), pp. 139-153

[5] http://www.tohotenax-eu.com, (accessed 09.07.2013)

[6] Krekel, G.; Hüttinger, J.; Hoffmann, W. P.; Silver, D. S.: The relevance of the surface structure and surface chemistry of carbon fibres in their adhesion to high -temperature thermoplastics, Journal of Materials Science, Part I Surface structure and morphology, 29(1994), pp. 2968-2980

[7] Lindsay, B.; Abeld, M.-L.; Watts, J. F.: A study of electrochemically treated PAN based carbon fibres by IGC and XPS, Carbon, 45(2007), pp. 2433-2444

[8] Mouritz, A. P.; Leong, K. H.; Herszberg, I.: A review of the effect of stitching on the in-plane mechanical properties of fibre-reinforced polymer composites, COMPOS PART A-APPL S, 28(1997), pp. 979-991

[9] Tang, L.-G; Kardos, J.-L.: A review of methods for improving the interfacial adhesion between carbon fiber and polymer matrix, Polymer Composites, 18(1997)1, pp. 100-113

[10] Yue, Z. R; Jiang, W.; Wand, L.; Gardner, S.D.; Pittmann, Jr. C. U.: Surface characterization of electrochemically oxidized carbon fibers, Carbon, 37(1999), pp. 1785-1796 